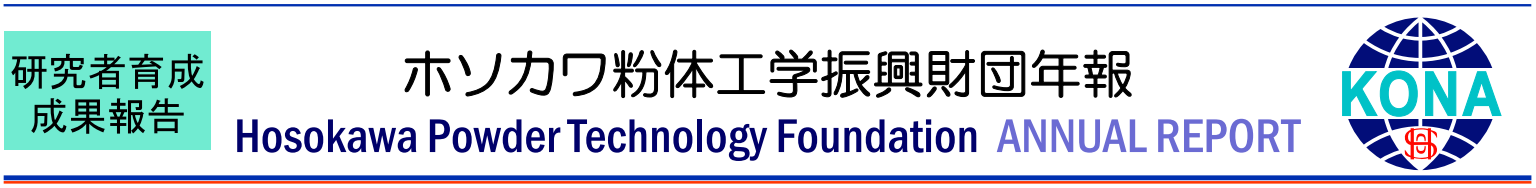

18509

\title{
悪酸化物ナノ粒子の合成と触媒特性評価 \\ Synthesis of Suboxide Nanoparticles \\ and Their Catalytic Properties
}

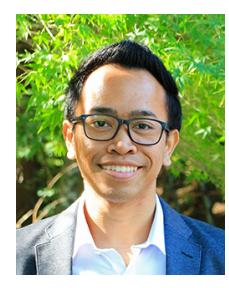

Febrigia Ghana RINALDI

\section{援助対象者 Scholarship Student: Febrigia Ghana RINALDI \\ 広島大学大学院工学研究科 博士課程後期 3 年 \\ Graduate school of Engineering, Hiroshima University, PhD Student (D3) \\ E-mail: ghanarinaldi@hiroshima-u.ac.jp}

\author{
研究指導者Academic Leader：荻 崇 Takashi OGI \\ 准教授, Associate Professor \\ E-mail: ogit@hiroshima-u.ac.jp
}

\section{成 果 の 概 要}

\section{Background}

In the past decade, tungsten oxide $\left(\mathrm{WO}_{3}\right)$ nanoparticles have attracted much attention as an efficient material for photocatalysis, phototherapy, and electrochemical applications, due to their favorable physical and chemical properties. Their relatively narrow band gap of 2.6-3.0 eV allows for excitation by visible wavelengths, which is desirable for photocatalysis applications. The favorable surface interaction between tungsten oxide and organic dye molecules also makes it a good adsorbent. The interaction between dye molecules and $\mathrm{WO}_{3}$ nanosheet surfaces has been reported previously. $\mathrm{WO}_{3}$ nanoparticles in the form of films or nanosheets were used as adsorbents, and exhibited selective adsorption properties, though the amount of adsorbed material was not high. Another report proposed the structuration of $\mathrm{WO}_{3}$ nanoparticles to enhance their surface area, which improved their adsorption properties and photocatalytic performance. A nonstoichiometric phase of $\mathrm{WO}_{3}$ known as tungsten blue oxide $\left(\mathrm{WO}_{x}\right)$ nanoparticles has recently received much interest. The presence of oxygen vacancies within its structure provides several advantages compared to $\mathrm{WO}_{3}$ (Song J. et al., 2015; Ghosh S. et al., 2015). For example, oxygen vacancies in the transition-metal oxide figuratively act as dopants, which decreases the band gap in a way similar to the addition of Pt onto $\mathrm{TiO}_{x}$ nanoparticles (Arif A.F. et al., 2017; Rinaldi F.G. et al., 2017). Hence, an intrinsic semiconductor can be converted to a hypothetically extrinsic semiconductor with a donor activation energy at $0.01 \mathrm{eV}$. $\mathrm{WO}_{x}$ nanoparticles also have the ability to generate free electrons $\left(\mathrm{N} \sim 10^{21} \mathrm{~cm}^{-3}\right)$. Numerous approaches have been developed for synthesis of $\mathrm{WO}_{x}$ nanoparticles, including approaches based on supercritical fluid, sol gel, hydrothermal, and chemical vapor deposition methods. $\mathrm{WO}_{x}$ particles can reportedly be produced by heating ammonium paratungstate 
for several hours, which is feasible for industrialscale applications. The use of $\mathrm{WO}_{x}$ particles in various forms and morphologies, such as $\mathrm{Ag} / \mathrm{WO}_{x}$ nanorods, $\mathrm{WO}_{x}-\mathrm{TiO}_{2}$ composites, $\mathrm{WO}_{x} / \mathrm{C}$ nanocomposites, and $\mathrm{WO}_{x}$ nanorods, for photocatalytic application has been previously reported. Such reports have shown that other than the presence of an additional dopant or cocatalyst, increasing the amount of oxygen vacancies inside the crystal structure could improve the photocatalytic performance. However, most resulting products were reportedly larger than $100 \mathrm{~nm}$. Nanosized particles (i.e., smaller than $100 \mathrm{~nm}$ ) are preferred because higher specific surface area gives them higher activity. To the best of our knowledge, there are still no reports on synthesis of $\mathrm{WO}_{x}$ nanoparticles smaller than $100 \mathrm{~nm}$ via thermal reduction methods at reduction temperatures in the range of $300-700^{\circ} \mathrm{C}$. Furthermore, there are also no reports regarding the effect of reduction temperature on their catalytic performances under dark condition and light irradiation for organic dye degradation.

In this study, $\mathrm{WO}_{x}$ nanoparticles were synthesized from plasma-synthesized $\mathrm{WO}_{3}$ nanoparticles via a thermal reduction process under $100 \% \mathrm{H}_{2}$ gas inside an electric furnace. The effect of the reduction temperature on the physicochemical properties of the resulting $\mathrm{WO}_{x}$ nanoparticles was investigated systematically. The degradation of rhodamine B (RhB) under dark conditions and visible light irradiation was studied to evaluate the adsorption and photocatalytic performance of the as-synthesized $\mathrm{WO}_{x}$ nanoparticles.

\section{Experimental}

$\mathrm{WO}_{x}$ nanoparticles were synthesized from plasma-synthesized $\mathrm{WO}_{3}$ nanoparticles (used as received from Nisshin Engineering Inc., Japan without any additional treatment) with an average particle size of $6 \mathrm{~nm}$. In a typical process, $0.5 \mathrm{~g}$ of plasmasynthesized $\mathrm{WO}_{3}$ nanoparticles were loaded into ce- ramic boats, which were placed in the center of the furnace. The reduction temperature was varied from 100 to $700^{\circ} \mathrm{C}$, with a heating rate of $10^{\circ} \mathrm{C} \mathrm{min}^{-1}$, and reduction was carried out for $1 \mathrm{~h}$. Throughout the entire process, high-purity $\mathrm{H}_{2}$ gas was flown into the furnace chamber at a rate $1 \mathrm{~L} \mathrm{~min}^{-1}$. A photoreactor system equipped with a solar simulator was used as the visible light source. In a typical degradation experiment, $100 \mathrm{mg}$ of $\mathrm{WO}_{x}$ nanoparticles was dispersed in $200 \mathrm{~mL}$ of $\mathrm{RhB}$ solution $\left(12 \mathrm{mg} \mathrm{L}^{-1}\right)$. The adsorption process was monitored under dark conditions for $3 \mathrm{~h}$ before starting the photocatalytic activity measurements. The photocatalytic activity was observed for $2 \mathrm{~h}$ under visible light irradiation. For this analysis, a UV-vis absorption spectrophotometer was used to obtain the absorption spectra of samples at given times.

\section{Result and discussion}

Fig. 1 shows X-ray diffraction (XRD) patterns of the plasma-synthesized $\mathrm{WO}_{3}$ nanoparticles and $\mathrm{WO}_{x}$ nanoparticles synthesized under reduction temperatures ranging from 100 to $700^{\circ} \mathrm{C}$ for $1 \mathrm{~h}$. The XRD pattern of the pale green $\mathrm{WO}_{3}$ nanoparticles could be assigned to the monoclinic crystal structure based on PDF no. 43-1035. The main diffraction peaks at $2 \theta=24.2,26.7$, and $34.0^{\circ}$ corresponded to the $(020)$, (200), and (202) planes, respectively. Similar XRD patterns were observed for the $\mathrm{WO}_{x}$ nanoparticles reduced at $100-300^{\circ} \mathrm{C}$. However, the color of the $\mathrm{WO}_{x}$ nanoparticles gradually changed from green to bluish green to teal blue. The change in color was caused by oxygen loss within the crystal structure, which led to a change in the $\mathrm{W}$ valence state. During reduction, some of the initial $\mathrm{W}^{6+}$ were reduced to $\mathrm{W}^{5+}$ and $\mathrm{W}^{4+}$, which were responsible for the color change of the nanoparticles. $\mathrm{WO}_{2.9}$ nanoparticles with a navy-blue color were obtained when the $\mathrm{WO}_{3}$ nanoparticles were reduced at $400^{\circ} \mathrm{C}$. The XRD pattern was consistent with PDF no. 05-0386 of the monoclinic $\mathrm{WO}_{2.9}$ crystal structure. As discussed 


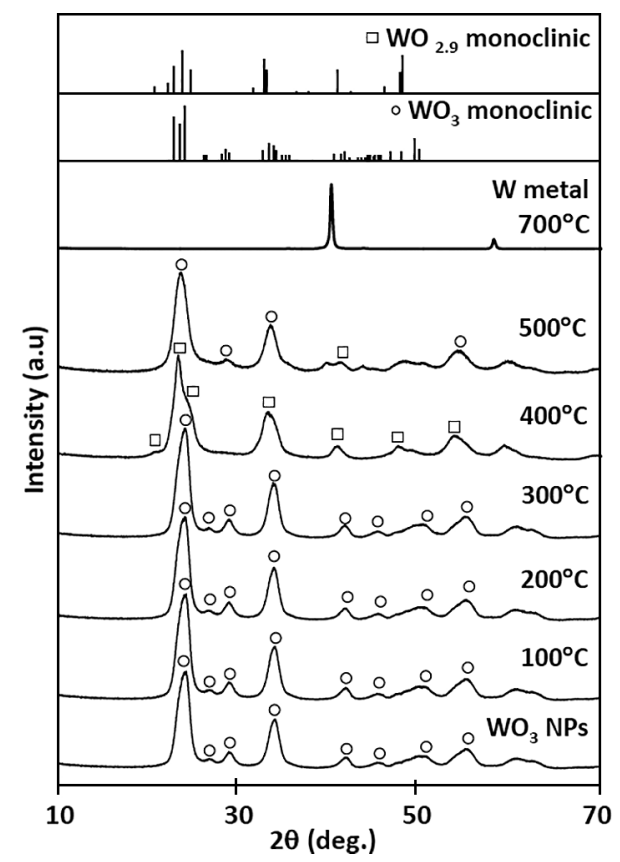

Fig. 1 XRD patterns of the $\mathrm{WO}_{3}$ nanoparticles and $\mathrm{WO}_{x}$ nanoparticles reduced at different temperatures for $1 \mathrm{~h}$ under a $\mathrm{H}_{2}$ gas atmosphere.

above, the darkening of the $\mathrm{WO}_{x}$ nanoparticle color was associated with an increase in the amount of oxygen deficiencies. More oxygen vacancies within the crystal structure resulted in darker particles. When the reduction temperature was increased to $500^{\circ} \mathrm{C}$, the dominant phase the $\mathrm{WO}_{x}$ nanoparticles was $\mathrm{WO}_{3}$ monoclinic crystal structure. A weak peak of $\mathrm{WO}_{2.9}$ monoclinic crystal structure was still observed, as well as new broad peaks at $2 \theta$ of $40-55^{\circ}$.

The color of the $\mathrm{WO}_{x}\left(500^{\circ} \mathrm{C}\right)$ nanoparticles was peacock blue violet. The broad peaks could be assigned to a set of complex structures of different phases of $\mathrm{WO}_{x}$ nanoparticles that were hard to distinguish. $\mathrm{WO}_{3}$ monoclinic peaks were observed because the nanoparticles had a very active surface, which rapidly oxidized when exposed to the atmosphere. When reduced at $700^{\circ} \mathrm{C}$, nanoparticles with a black color were obtained. The XRD pattern showed that the $\mathrm{WO}_{x}\left(700^{\circ} \mathrm{C}\right)$ nanoparticles were pure $\mathrm{W}$ metal, and that the $\mathrm{WO}_{3}$ nanoparticles had been over reduced.

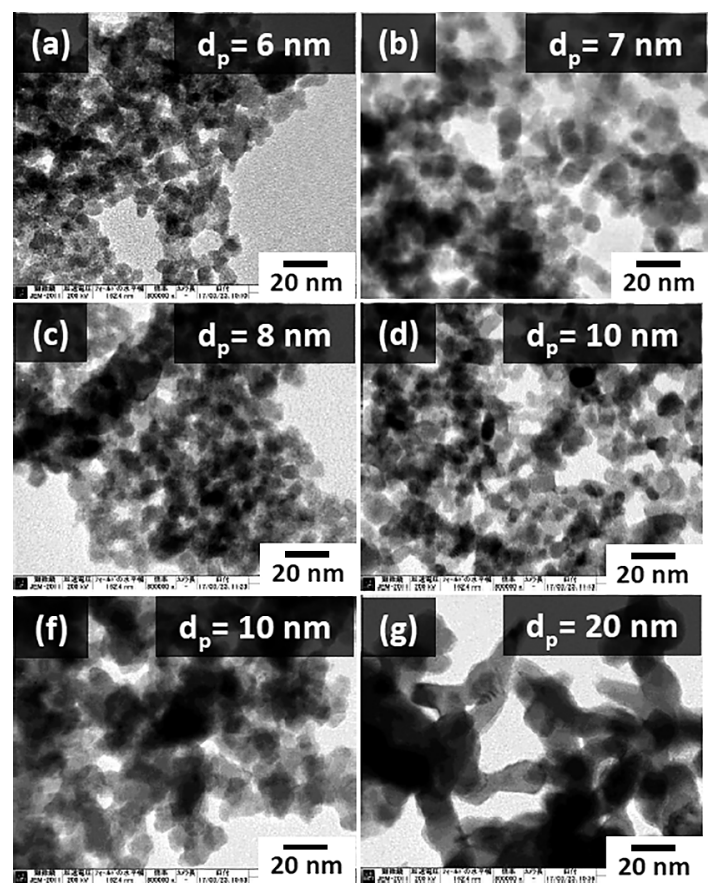

Fig. 2 TEM images of the (a) $\mathrm{WO}_{3}$ nanoparticles and $\mathrm{WO}_{x}$ nanoparticles reduced at (b) $100^{\circ} \mathrm{C}$, (c) $200^{\circ} \mathrm{C}$, (d) $300^{\circ} \mathrm{C}$, (e) $400^{\circ} \mathrm{C}$, (f) $500^{\circ} \mathrm{C}$, and (g) $700^{\circ} \mathrm{C}$.

Fig. 2 shows transmission electron microscopy (TEM) images of the $\mathrm{WO}_{3}$ nanoparticles and $\mathrm{WO}_{x}$ nanoparticles synthesized under different reduction temperatures for $1 \mathrm{~h}$. Fig. 2a shows the pristine $\mathrm{WO}_{3}$ nanoparticles, which had an average diameter $\left(d_{\mathrm{p}}\right)$ of $6 \mathrm{~nm}$. Increasing the reduction temperature from 100 to $500^{\circ} \mathrm{C}$ yielded monodisperse $\mathrm{WO}_{\mathrm{x}}$ nanoparticles with $d_{\mathrm{p}}$ values of 7-11 nm, respectively, as shown in Fig. 2 b-f. Fig. 2 g shows a TEM image of the sample prepared at $700^{\circ} \mathrm{C}$, in which the nanoparticles were sintered with a $d_{\mathrm{p}}$ of approximately $20 \mathrm{~nm}$. $\mathrm{WO}_{3}$ nanoparticles reportedly readily sinter at annealing temperatures higher than $300^{\circ} \mathrm{C}$.

Fig. 3 shows the degradation of RhB solution as a function of time over the $\mathrm{WO}_{3}$ nanoparticles and $\mathrm{WO}_{x}$ nanoparticles reduced at different temperatures. The degradation process of RhB, which includes adsorption and photocatalysis processes, is shown in Fig. 3a. Fig. 3b shows a plot of their corresponding $-\ln \left(C / C_{0}\right)$ values against the visible light 

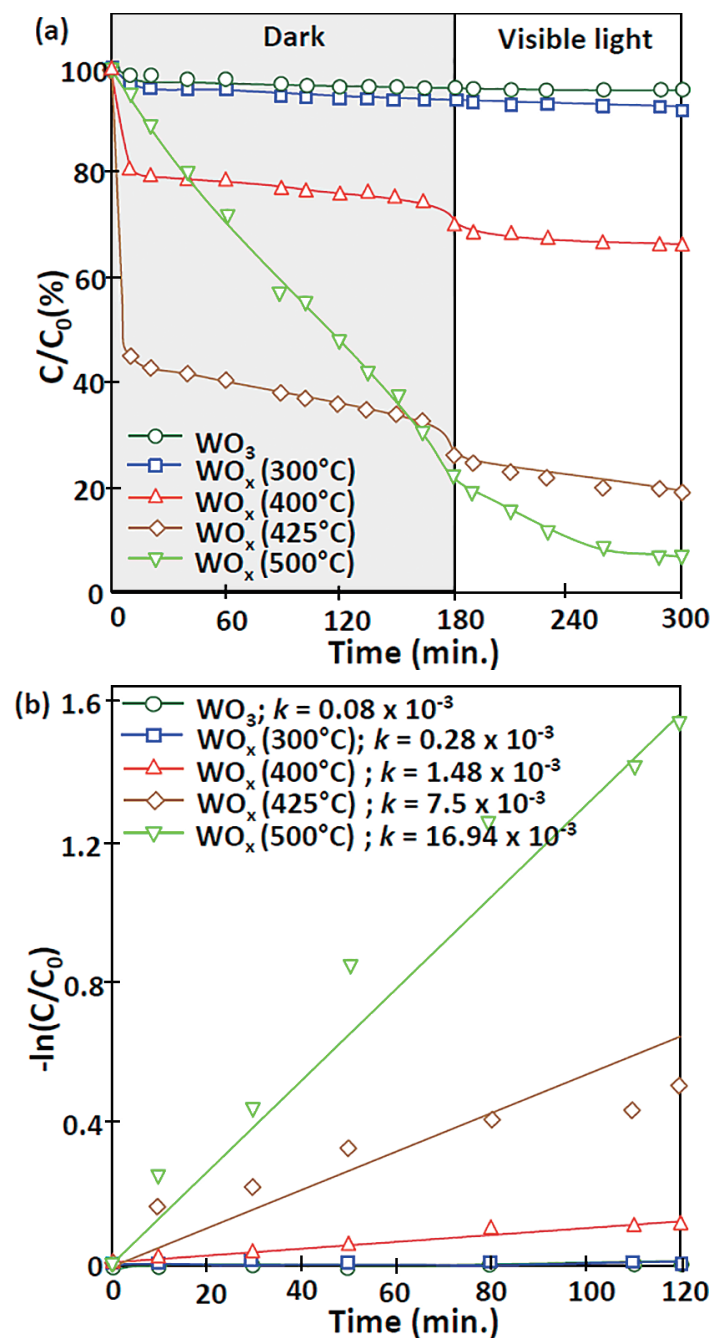

Fig. 3 (a) Degradation profiles of $\mathrm{RhB}$ over the $\mathrm{WO}_{3}$ nanoparticles and $\mathrm{WO}_{x}$ nanoparticles (b) $-\ln \left(C / C_{0}\right)$ versus irradiation time plots.

irradiation time. $C$ and $C_{0}$ represent the concentration of RhB solution at any given time and its initial concentration, respectively.

Fig. 3a shows that the adsorption-desorption equilibriums of RhB in dark conditions over the $\mathrm{WO}_{3}$ nanoparticle and $\mathrm{WO}_{x}\left(300^{\circ} \mathrm{C}\right)$ nanoparticle surfaces occurred after approximately $10 \mathrm{~min}$. The $\mathrm{RhB}$ concentration after measurement for $3 \mathrm{~h}$ in dark conditions and $2 \mathrm{~h}$ under visible light irradiation over the $\mathrm{WO}_{x}\left(300^{\circ} \mathrm{C}\right)$ nanoparticles decreased only slightly from that over the $\mathrm{WO}_{3}$ nanoparticles. The corresponding $\mathrm{RhB}$ concentrations were 93 and $96 \%$. The rate constant $(k)$ for the photodecomposi- tion of $\mathrm{RhB}$ under visible light irradiation by each sample was evaluated using simplified LangmuirHinshelwood kinetics, and the results are shown in Fig. 3b. The $\mathrm{WO}_{x}\left(400^{\circ} \mathrm{C}\right)$ nanoparticles showed higher adsorption and photocatalytic performance, with remaining RhB concentrations of 74 and $66 \%$ after measurement in dark conditions for $3 \mathrm{~h}$ and under visible light irradiation for $2 \mathrm{~h}$, respectively. The $k$ value for this sample was $1.48 \times 10^{-3} \mathrm{~min}^{-1}$. The degradation of RhB increased significantly when the $\mathrm{WO}_{x}$ nanoparticles were reduced at $425^{\circ} \mathrm{C}$. The remaining $\mathrm{RhB}$ concentrations for these nanoparticles were approximately 30 and 19\% after measurements in dark conditions and under visible light irradiation, respectively, and the $k$ value was $7.5 \times 10^{-3} \mathrm{~min}^{-1}$. This $k$ value was 93 times higher than that for the $\mathrm{WO}_{3}$ nanoparticles. The above results indicated that the amount of RhB adsorbed on the particle surface increased as the reduction temperature increased.

\section{References}

Arif A.F., Balgis R., Ogi T., Iskandar F., Kinoshita A., Nakamura K., Okuyama K., Highly conductive nano-sized Magnéli phases titanium oxide $\left(\mathrm{TiO}_{x}\right)$, Scientific Reports, 7 (2017) 3646.

https://doi.org/10.1038/s41598-017-03509-y

Ghosh S., Saha M., Paul S., De S., Maximizing the photo catalytic and photo response properties of multimodal plasmonic $\mathrm{Ag} / \mathrm{WO}_{3-x}$ heterostructure nanorods by variation of the Ag size, Nanoscale, 7 (2015) 18284-18298. https://doi.org/10.1039/C5NR05185A

Rinaldi F.G., Arif A.F., Ogi T., Okuyama K., Tanabe E., Strong metal-support interactions (SMSIs) between Pt and $\mathrm{Ti}^{3+}$ on $\mathrm{Pt} / \mathrm{TiO} x$ nanoparticles for enhanced degradation of organic pollutant, Advanced Powder Technology, 28 (2017) 2987-2995.

https://doi.org/10.1016/j.apt.2017.09.007

Song J., Huang Z.-F., Pan L., Zou J.-J., Zhang X., Wang L., Oxygen-deficient tungsten oxide as versatile and efficient hydrogenation catalyst, ACS Catalysis, 5 (2015) 6594-6599. https://doi.org/10.1021/acscatal.5b01522 
外部発表成果

\section{論文発表}

1. Rinaldi F.G., Arutanti O., Arif A.F., Hirano T.,
Ogi T., Okuyama K., Correlations between reduction degree and catalytic properties of $\mathrm{WO}_{x}$ nanoparticles, ACS Omega, 3(8) (2018) 89638970. https://doi.org/10.1021/acsomega.8b01110 